\title{
Factors influencing social activism among campus: Youth in Sri Lanka
}

\begin{abstract}
Youths are constantly searching for a social identity and citizenry to express their inner concerns, and realize their national development. Within this context, this study identifies social activism as a means for building youths' identity and citizenry. Numerous studies have indicated that the search for identity and citizenry is greatly influenced by both contextual and demographic factors. This paper aims to discuss the findings of a study pertaining to the contextual and demographic variables that influence social activism among campus youths in Sri Lanka. Corning's measures of Social Activism Orientation were adapted for this study to measure social activism. The findings of this study suggest that youths, irrespective of rural and urban, coming from low income or high income households, belonging to different fields of studies or have parents with different levels of engagement in political activities, have equal levels of engagement in social activism in college campuses. However, significant differences were indicated between youths' gender, war and non-war location context, and if their campuses are long established or newly established universities. The impact of universal free education policy is discussed with special reference to youth empowerment. Existing constrains and the lack of a youth - centered development approach, together with existing institutional socio political culture on campus are also discussed.
\end{abstract}

Keyword: Social Activism, Campus Youth, Sri Lanka 